\title{
Newborn Screening for Primary Immunodeficiency Diseases: The Past, the Present and the Future
}

\author{
Jovanka King 1,2 (D), Jonas F. Ludvigsson ${ }^{3,4}$ and Lennart Hammarström ${ }^{1, *}$ \\ 1 Department of Clinical Immunology, Karolinska University Hospital Huddinge, SE-14186 Stockholm, \\ Sweden; jovanka.king@ki.se \\ 2 Department of Immunopathology, SA Pathology, Women's and Children's Hospital Campus, \\ Robinson Research Institute and Discipline of Paediatrics, School of Medicine, University of Adelaide, \\ North Adelaide 5006, Australia \\ 3 Department of Medical Epidemiology and Biostatistics, Karolinska Institutet, SE-10435 Stockholm, Sweden; \\ jonas.ludvigsson@ki.se \\ 4 Department of Gastroenterology, Faculty of Medicine and Health, Örebro University, \\ SE-70281 Örebro, Sweden \\ * Correspondence: lennart.hammarstrom@ki.se
}

Received: 18 July 2017; Accepted: 1 August 2017; Published: 3 August 2017

\begin{abstract}
Primary immunodeficiency diseases (PID) are a heterogeneous group of disorders caused by inborn errors of immunity, with affected children presenting with severe, recurrent or unusual infections. Over 300 distinct genetic molecular abnormalities resulting in PID have been identified, and this number continues to rise. Newborn screening for PID has been established in many countries, with the majority of centers using a PCR-based T cell receptor excision circle (TREC) assay to screen for severe combined immunodeficiency (SCID) and other forms of T cell lymphopenia. Multiplexed screening including quantitation of kappa-recombining exclusion circles (KREC) has also been described, offering advantages over TREC screening alone. Screening technologies are also expanding to include protein-based assays to identify complement deficiencies and granulocyte disorders. Given the rapid advances in genomic medicine, a potential future direction is the application of next-generation sequencing (NGS) technologies to screen infants for a panel of genetic mutations, which would enable identification of a wide range of diseases. However, several ethical and economic issues must be considered before moving towards this screening strategy.
\end{abstract}

Keywords: newborn screening; primary immunodeficiency diseases; TREC; KREC; next-generation sequencing

\section{Introduction}

Primary immunodeficiency diseases (PID) are a heterogeneous group of disorders which are genetically determined inborn errors of immunity. In excess of 300 distinct genetic molecular abnormalities resulting in PID have been identified, and this number continues to increase. Based on estimates from the human connectome, more than 1000 genes interact with known PID genes [1]. Children with PID present with severe, recurrent or unusual infections, and these diseases are associated with significant morbidity and mortality. Until recent years, there was no available testing modality to identify these children prior to the onset of symptoms, frequently resulting in delayed diagnosis and treatment, and a complicated clinical course. Currently available newborn screening technologies have enabled the early identification of severe forms of PID, manifested by $\mathrm{T}$ and $\mathrm{B}$ cell lymphopenia, which has been demonstrated to have a profound impact on patient outcomes [2]. PID were previously thought to represent rare disease entities, however through newborn screening programs, true disease incidence rates can be determined and have proven to be higher than expected. 
Newborn screening for PID continues to be an evolving field, with the potential for future expansion to include screening for other forms of PID such as granulocyte disorders and complement deficiency. The future of newborn screening for the identification of PID and other inborn errors is likely to involve a change in screening strategy, where next-generation sequencing will have an increasingly prominent role, potentially even as up-front testing. Here, we review the past and present aspects of newborn screening for primary immunodeficiency diseases, and discuss potential future directions.

\section{The Past: Identification of Severe Combined Immunodeficiency as a Priority for Newborn Screening}

Since the initiation of population-based newborn screening using dried blood spots (DBS) in the 1960s using a method established by Guthrie and Susi [3], there have been significant advances in our ability to screen asymptomatic infants for severe, life-threatening diseases for which treatment is available, and where early diagnosis and treatment is essential for preventing serious sequelae. For inclusion in population-based screening programs, diseases must meet a series of criteria as described by Wilson and Jungner [4]. Severe combined immunodeficiency (SCID) is a life-threatening condition resulting from a profound lymphocyte deficiency. It manifests with significant infections and is uniformly fatal without treatment. SCID is curable with hematopoietic stem cell transplantation (HSCT), and it has been demonstrated that outcomes are markedly improved for infants who are diagnosed and undergo HSCT prior to the age of 3.5 months [2]. Diagnosis and treatment is frequently delayed, and realistically, achieving this target is only possible if affected newborns are identified by screening prior to the onset of symptoms, acquisition of infections and other complications. As such, SCID meets the necessary criteria and is a suitable candidate for population-based newborn screening, and this has been borne out in prospective screening trials $[5,6]$.

\section{The Present: Screening for T and B Cell Lymphopenia}

A seminal paper was published by Chan and Puck in 2005, describing the T-cell receptor excision circles (TREC) assay for the detection of SCID in a newborn screening setting [7]. TREC are small, circular pieces of episomal DNA which are produced during T cell receptor (TCR) rearrangement in naïve $\mathrm{T}$ cells, which serve as a surrogate marker of recent thymic emigrants. TREC copy numbers, measurable by quantitative reverse transcription polymerase chain reaction (qRT-PCR), are markedly reduced or absent in infants with SCID and other forms of T cell lymphopenia. Screening for SCID has become part of routine newborn screening programs in all US states, the District of Columbia and the Navajo Nation (Jeffrey Modell Foundation, http:/ / www.info4pi.org). Several countries in Europe, Australasia and the Middle East have also commenced SCID screening programs, or are evaluating these in prospective studies (Table 1).

Table 1. Worldwide status of newborn screening programs for primary immunodeficiency diseases (PID). TREC: T-cell receptor excision circles; KREC: kappa-recombining exclusion circles; ADA: adenosine deaminase.

\begin{tabular}{cccc}
\hline Country & Screening Strategy & Date of Commencement & Reference \\
\hline $\begin{array}{c}\text { United States of America } \\
\begin{array}{c}\text { All 50 States } \\
\text { District of Columbia } \\
\text { Navajo Nation }\end{array}\end{array}$ & TREC & $\begin{array}{c}2008 \text { (Wisconsin) } \\
\text { National implementation }\end{array}$ & $\begin{array}{c}\text { Dorsey \& Puck 2017 [8] } \\
\text { http://www.info4pi.org/ }\end{array}$ \\
\hline Italy & & & http://ipopi.org/ \\
Tuscany & & 2010: Pilot study & 2010: Pilot study \\
Umbria & TREC/ADA & 2013: Pilot study & \\
Florence & &
\end{tabular}


Table 1. Cont.

\begin{tabular}{|c|c|c|c|}
\hline Country & Screening Strategy & Date of Commencement & Reference \\
\hline Taiwan & TREC & $\begin{array}{l}\text { 2010: Pilot study } \\
\text { 2012: National implementation }\end{array}$ & Chien YH et al., 2017 [9] \\
\hline Israel & TREC & $\begin{array}{l}\text { 2011: Pilot study } \\
\text { 2015: National implementation }\end{array}$ & Rechavi et al., 2017 [10] \\
\hline The Netherlands & TREC & $\begin{array}{l}\text { 2012: Pilot study } \\
\text { 2015: Application approved }\end{array}$ & $\begin{array}{l}\text { Blom et al., } 2017 \text { [11] } \\
\text { http://ipopi.org/ }\end{array}$ \\
\hline Qatar & TREC & 2012: National implementation & http://ipopi.org/ \\
\hline Germany & TREC/KREC & $\begin{array}{c}\text { 2013: Pilot study } \\
\text { Application in progress }\end{array}$ & http://ipopi.org/ \\
\hline Sweden & TREC/KREC & 2013: Pilot study & Barbaro et al., 2016 [6] \\
\hline Japan & TREC/KREC & 2014: Pilot study & http://ipopi.org/ \\
\hline France & TREC & 2014: Pilot study & $\begin{array}{l}\text { Audrain et al., } 2014 \text { [12] } \\
\text { http://ipopi.org/ }\end{array}$ \\
\hline $\begin{array}{c}\text { Spain } \\
\text { Andalucia }\end{array}$ & TREC/KREC & 2014: Pilot study & $\begin{array}{l}\text { de Felipe et al., } 2016 \text { [13] } \\
\text { http:/ / ipopi.org/ }\end{array}$ \\
\hline Norway & TREC & 2015: Pilot study & http://ipopi.org/ \\
\hline Puerto Rico & TREC & 2016: National implementation & $\begin{array}{l}\text { Dorsey \& Puck 2017 [8] } \\
\text { http:// www.info4pi.org/ }\end{array}$ \\
\hline New Zealand & TREC & 2017: Due to commence & http://ipopi.org/ \\
\hline $\begin{array}{c}\text { Canada } \\
\text { Ontario } \\
\text { British Columbia } \\
\text { Yukon } \\
\text { Prince Edward Island } \\
\text { Nova Scotia } \\
\text { New Brunswick }\end{array}$ & TREC & $\begin{array}{l}\text { Screening underway } \\
\text { Approved, pending funding } \\
\text { Approved, pending funding } \\
\text { Approved, pending funding } \\
\text { Approved, pending commencement } \\
\text { Approved, pending commencement }\end{array}$ & http://ipopi.org/ \\
\hline Brazil & TREC & Pilot study & Kanegae et al., 2016 [14] \\
\hline Denmark & TREC & $\begin{array}{l}\text { Application in progress } \\
\text { Pilot study }\end{array}$ & http://ipopi.org/ \\
\hline Iceland & TREC/KREC & $\begin{array}{l}\text { Application in progress } \\
\text { Pilot study }\end{array}$ & http://ipopi.org/ \\
\hline Iran & TREC/KREC & Pilot study & Personal communication \\
\hline Saudi Arabia & TREC/KREC & Pilot study & http://ipopi.org/ \\
\hline Slovenia & & $\begin{array}{c}\text { Pilot study } \\
\text { Application in progress }\end{array}$ & http://ipopi.org/ \\
\hline Turkey & TREC/KREC & Pilot study & Personal communication \\
\hline United Kingdom & TREC & $\begin{array}{l}\text { Application in progress } \\
\text { Pilot study }\end{array}$ & http://ipopi.org/ \\
\hline Australia & & Application in progress & http://ipopi.org/ \\
\hline Austria & TREC/KREC & Application in progress & http://ipopi.org/ \\
\hline $\begin{array}{l}\text { Belgium } \\
\text { Flanders }\end{array}$ & TREC/KREC & $\begin{array}{l}\text { Application in progress } \\
\text { Application in progress }\end{array}$ & $\begin{array}{c}\text { Personal communication } \\
\text { http://ipopi.org/ }\end{array}$ \\
\hline Czech Republic & TREC/KREC & Application in progress & Personal communication \\
\hline Poland & & Application in progress & http://ipopi.org/ \\
\hline Portugal & & Application in progress & http://ipopi.org/ \\
\hline Romania & & Application in progress & http://ipopi.org/ \\
\hline Switzerland & TREC/KREC & Application in progress & http://ipopi.org/ \\
\hline United Arab Emirates & & Applications in progress & http://ipopi.org/ \\
\hline
\end{tabular}

In addition to the detection of TREC levels as surrogate markers for thymic T cell output, it is also possible to evaluate B cell production by quantifying kappa-recombining excision circles (KREC), which are produced by similar mechanisms during rearrangement of the variable, diversity and joining domains ( $\mathrm{V}(\mathrm{D}) \mathrm{J}$ recombination) of the B cell immunoglobulin kappa gene [15]. A multiplexed assay measuring TREC and KREC, along with beta-actin levels as a control for DNA quantity provides a strategy for simultaneous screening for $\mathrm{T}$ and $\mathrm{B}$ cell lymphopenia [16]. 
Screening for PID by measuring both TREC and KREC offers advantages over TREC screening alone. This includes identification of patients with X-linked agammaglobulinemia (XLA), an antibody deficiency disorder caused by mutations in the BTK gene which is essential for B cell development. Consequently, there is an absence of B cells, lack of antibody production, and severe infections with bacteria and other pathogens [17-19]. Mutations in other genes involved in B cell development have also been described, giving rise to an XLA-like disease with a similar phenotype [20]. Both groups of patients can be identified by low or absent KREC levels. Early identification of this disease is important, as it facilitates timely commencement of gammaglobulin replacement therapy. In addition to XLA, multiplexed TREC/KREC screening also facilitates diagnosis of individuals with late onset adenosine deaminase (ADA) deficiency, some cases of Nijmegen breakage syndrome (NBS) and other forms of PID which may otherwise be missed [16]. In the case of SCID, combined screening aids in the diagnostic process and guides targeted molecular evaluation, as different mutations will give rise to a variable pattern of T and B cell deficiency. Potential increased costs associated with KREC screening in addition to TREC screening have been suggested as a disadvantage of combined screening. Intrinsic costs of laboratory testing, patient follow-up and second tier testing must all be considered. However, the additional costs of adding KREC quantitation to a TREC-only platform are negligible, estimated to be less than $€ 0.10$ per test. Another proposed disadvantage of combined TREC/KREC screening was a higher recall rate for abnormal KREC levels. However, results of our recent evaluation of the combined TREC/KREC newborn screening program in Sweden show that the recall rate is dependent upon cut off levels set, but the recall rate in our cohort was similar to that for TREC-only testing programs [6], suggesting that this was unlikely to be an issue. There are some limitations of TREC-based screening. Some cases of SCID will not be identified, in the case where T cells are present but have abnormal function, or where the molecular defect lies downstream of TCR rearrangement (including Zap70 Deficiency, major histocompatibility complex (MHC) class II deficiency and some cases of delayed-onset adenosine deaminase (ADA) deficiency) [21-26].

\section{The Future: Screening for Other Forms of PID}

In addition to screening for immunodeficiency diseases that manifest with $\mathrm{T}$ and $\mathrm{B}$ cell lymphopenia, expanded screening for the detection of other diseases such as complement deficiencies and granulocyte disorders using protein-based assays has also been proposed. Disorders of granulocyte number and function give rise to severe, recurrent bacterial and fungal infections, and one possible method to identify these diseases involves measurement of granulocyte-specific proteins. The complement system consists of a large number of interacting components. Individuals with complement deficiency present variably, with significant bacterial infections caused by specific pathogens, or severe autoimmune or renal disease. In these patients, complement protein levels are reduced as a result of the underlying genetic mutation. It has been demonstrated that complement proteins can be eluted from DBS samples, allowing identification of C2- and C3-deficient patients at birth who have low or absent protein levels $[27,28]$. This can ultimately be expanded to develop multiplexed assays which enable detection of multiple complement cascade components and granulocyte specific proteins to enable detection of these disorders in the neonatal period, which would enable early diagnosis and treatment, minimizing long-term complications in these patients. Screening for granulocyte disorders and complement deficiency will be covered elsewhere in greater detail in this special issue on newborn screening for PID.

Targeted genetic testing is another newborn screening approach, and this is currently employed in screening algorithms for selected diseases such as cystic fibrosis [29]. Familial hemophagocytic lymphohistiocytosis (FHL) is a primary immunodeficiency disorder manifesting with a life-threatening inflammatory response secondary to impaired lymphocyte cytotoxicity. Several causative genetic mutations have been identified [20]. In Scandinavia, 50\% of FHL cases are due to homozygous UNC13D inversion mutations, and a screening strategy based on the detection of reduced UNC13D wild type gene copy numbers was demonstrated to be an effective method by which to identify affected 
individuals [30]. This approach could be expanded to enable identification of mutations in other FHL genes, and may have a role in screening for other disorders.

\section{The Future: The Role of Next-Generation Sequencing in Newborn Screening for PID}

Since completion of sequencing of the human genome project in 2003, advances in next-generation sequencing have progressed exponentially, resulting in an increased availability of testing, improved bioinformatic pipelines for data analysis, a faster turn-around time and a decrease in associated costs. This makes next-generation sequencing (NGS) an attractive and affordable modality to employ not only in a diagnostic setting, but also as a potential screening tool. Given that there is no single or multiplexed screening assay which can reliably detect all forms of PID at birth, we propose a screening approach for PID where all newborns undergo whole genome sequencing (WGS), with rapid analysis of the currently known $300+$ genes, which would be expanded to include additional clinically relevant genes as they are identified.

Current strategies for newborn screening include metabolic assays, TREC/KREC quantification and targeted genetic studies, and this list is expected to expand. Second- and third-tier testing is required to confirm the findings of the screening test, and to make a specific diagnosis. Targeted mutation analysis or next-generation sequencing, including whole exome sequencing (WES) and whole genome sequencing, is often required to determine the underlying molecular diagnosis. At the Center for Metabolic Diseases (CMMS) at the Karolinska University Hospital in Stockholm, an aberrant result on first-tier metabolic testing that cannot be rapidly confirmed with a second-line test is further evaluated by genetic testing by WGS. This enables specific mutations to be identified in known disease-causing genes. If no mutation is found, parents are counselled and consented to undergo further genomic evaluation [31]. In this model, an aberrant test is followed up with WGS. As such, the next logical step in screening methodology would be to screen newborns for a range of genetic mutations using up-front NGS. With targeted sequencing being of limited value and the technical limitations of WES, WGS seems the most appropriate choice.

Pavey et al. recently reported the results of WGS-based screening for PID in a cohort of 1349 newborn and parent trios, who were analyzed for variants in 329 known immunodeficiency genes [32]. A genotype-first pipeline resulted in identification of 396 newborns with pathogenic/likely pathogenic mutations, however on further analysis, only one individual was found to have a genomically predicted immunodeficiency (complement component C9 deficiency). C9 deficiency is associated with an increased risk of life-threatening Neisserial infection [20], and early institution of prophylactic measures including immunization are of utmost importance in this patient group. A phenotype-first pipeline was also applied, in which 29 infants were identified to have clinical features suggestive of possible immunodeficiency, but did not have an identifiable mutation in any of the interrogated PID genes. Three of these children had pathogenic mutations in other (non-PID) genes which correlated clinically. No additional causative variants were found in the other children, the majority of whom were considered to be unlikely to have a PID [32]. These findings are consistent with results of a survey conducted by Boyle et al., who determined a PID prevalence of 1 in 1200 in the US [33]. Taken together, it is expected that screening 1000 newborns will identify one case of PID, however utilizing a NGS approach enables identification of other disorders. This is the first reported study evaluating genomic testing for PID as a first-line screening strategy in newborns. Longer-term clinical follow-up in cohorts such as these, and larger studies are required to determine test characteristics such as sensitivity and specificity.

The National Institutes of Health are currently undertaking the 'Newborn Sequencing in Genomic Medicine and Public Health' (NSIGHT) project which will evaluate the role of up-front genomic testing in neonates (https:/ / www.genome.gov). These projects will include evaluation of exome sequencing in newborn screening for currently screened and additional disorders, and investigate the role of rapid turnaround genomic sequencing in the neonatal intensive care unit setting. They will also address key ethical, legal and social implications of implementation of such programs. This will involve 
evaluating parental experiences related to receiving clinical information arising from genomic testing in the newborn period, and medical practitioner experiences in terms of utilizing genomic information and its impact upon clinical care delivery [34].

The notion of performing WGS on every infant at birth is controversial, and there are several factors that need to be considered regarding this potential approach to screening. The Global Alliance Paediatric Task Team recently published a series of recommendations regarding this screening approach, highlighting clinical utility, management of incidental findings, cost-effectiveness, data management, and ethical, legal and social implications as key areas for consideration [35].

\subsection{Identification of Candidate Diseases and Genes to Be Evaluated in Newborn Genomic Screening Programs}

The identification of key diseases for inclusion in genomic-based screening programs, selection of appropriate gene candidates for interrogation, and establishment of a testing panel are major considerations. In terms of screening for PID, an approach similar to that adopted by Pavey et al. [32] involving interrogation of a gene panel inclusive of the currently-described 300+ PID genes is an appropriate starting point. However, such panels would need to be regularly updated to include newly identified genes. It is probable that patients without identifiable molecular causes for their disease will have mutations in novel genes, and hence frequent revision of gene panels will enhance our future diagnostic capabilities. Although we advocate for the use of WGS as a screening tool for all newborns, this must proceed with caution. More than 8000 Mendelian diseases are currently recognized (https://omim.org/), however, initial evaluation in a WGS-based newborn screening program should only involve interrogation of genetic mutations which have a definite disease-causing role and where a clear genotype/phenotype correlation exists. However, it is expected that over time, there will be an increase in the number of screened genetic mutations and diseases.

In order to gain an appreciation of which disorders were likely to be significant causes of child mortality, and hence, possible disease candidates for newborn screening, we evaluated the causes of death in children less than 18 years of age in Sweden between 1987 and 2015 (Figure 1). There were 19,957 deaths during this time period. Seventy-six deaths $(0.38 \%)$ were attributable to a known primary immunodeficiency disorder. Of these 76 cases, one death was attributed to common variable immunodeficiency, 4 to PID with predominant antibody deficiency, 5 to PID in combination with other major defects, 13 to combined immunodeficiency (including SCID), and 53 were attributed to unspecified immunodeficiency diseases. In addition, 849 deaths $(4.3 \%)$ were due to infectious diseases and their complications, and it is likely that there were a considerable number of additional cases of undiagnosed PID in this group. Tambe et al. evaluated causes of child and infant mortality in the United Kingdom between 2006 and 2008, and found a mortality rate due to diseases of the blood, blood-forming organs and the immune system of 1.8 per 1,000,000 children in the 5-15 year age group [36], and 3.3 per 100,000 children aged less than 5 years [37]. Infectious diseases accounted for 9.5 deaths per 1,000,000 in the 5-15 year age group [36], and 27.9 per 100,000 neonates and 36 per 100,000 children aged 28 days to 4 years [37]. There are some limitations of the studies performed by our group and Tambe et al., given the degree of subjectivity in International Classification of Diseases (ICD) code assignment and potential categorization of a disease in different groups, and some cases might not be captured correctly due to a lack of detailed coding [23]. In addition, this type of analysis does not capture the significant morbidity associated with survivorship of severe diseases such as PID. Evaluation of such data facilitates identification of key diseases that result in death or significant morbidity in infancy and childhood, which should therefore be prioritized as candidates for inclusion in population-based newborn screening programs. 


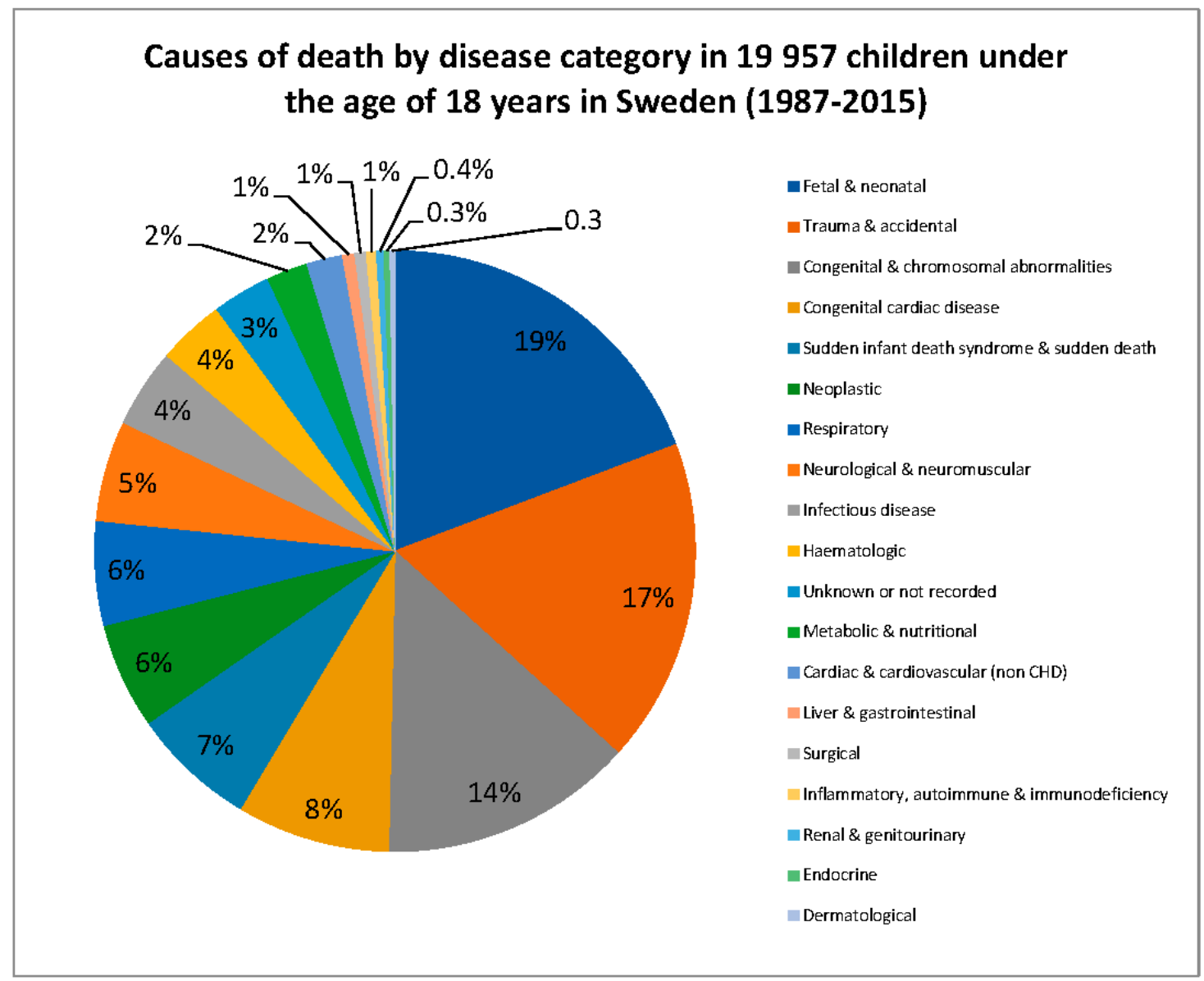

Figure 1. Causes of death by disease category in 19,957 children under the age of 18 years in Sweden (1987-2015).

\subsection{Establishment of Robust and Cost-Effective Genomic Testing Systems}

As for any diagnostic or screening assay, test characteristics must be agreeable, and an appropriate screening system must be established. All tests should be sufficiently sensitive and specific. A robust pipeline would be required, with a plan in place for data management, analysis and storage. Systems must also be established for managing abnormal results, with seamless integration with clinical services and timely access to clinical review, further testing, and management. A fast turn-around time, from sample collection to release of results is also essential to avoid any diagnostic delays. Furthermore, the process must be cost effective. A formal economic analysis is required to demonstrate that this approach is more cost effective than conventional screening strategies. There has been a significant decrease in assay-specific costs over time. Illumina, Inc. predict that in the near future, they will provide a WGS platform that will cost less than USD100 per genome (https:/ / www.illumina.com).

\subsection{Ethical, Legal and Social Implications}

Population-based NGS screening raises several ethical, legal and social issues that must be considered, and are not discussed here in detail. These considerations represent a key area which will be addressed through the NSIGHT projects and similar studies evaluating newborn screening using genomic testing. In many countries, newborn screening is offered as a standard of care, and consent is typically obtained via an 'opt out' process. A change in approach to NGS screening would lead to an added level of consent that needs to be obtained from families given the implications of genetic testing. There is a risk that this could potentially deter families from engagement in screening 
programs. Genetic data storage and management, biobanking of genetic material and its implications for other uses must also be considered. Variants of unknown significance are commonly found in NGS analyses. A clear plan must be established for the identification and reporting of such results. In addition, the finding of 'unexpected' or unrelated genetic mutations may have far-reaching effects on the individual and their family. The potential for identification of mutations in genes known to lead to debilitating or lifespan-reducing disease later in life for which no treatment exists must be considered, and how this will be managed should also be considered.

\subsection{A New Model for Newborn Screening}

Population-based NGS screening strategies represent a reversed approach to current screening practices, where typically a marker of disease is identified by a screening test, and then confirmed by genetic analysis. It stands to be determined if an upfront NGS testing approach will ultimately save time or money, given that functional tests may then be needed to confirm the genotype-phenotype correlation. This also raises the question as to if NGS screening will ultimately replace current screening tests, or if they would continue to be run in tandem. It is anticipated that the results of prospective genomic-based newborn screening programs will answer many of these questions, and inform future practice.

\section{Conclusions}

In the past, there was no method by which to identify infants with severe forms of PID, resulting in delayed diagnosis and significant complications. At the present time, newborn screening for the detection of severe forms of PID manifest by $\mathrm{T}$ and/or $\mathrm{B}$ cell lymphopenia using TREC or TREC/KREC screening has been established in many countries. There is the potential for future expansion to employ other screening modalities, such as protein-based assays and targeted genetic sequencing to enable identification of other forms of PID. However, it is not currently possible to screen for a wide range of diseases simultaneously using a single modality. It seems logical that the most effective and efficient way to screen newborns for an extensive list of diseases, which differ in terms of classification, pathophysiology and manifestation is using an up-front NGS testing strategy. Prior to adopting a genomic screening approach, selection of appropriate gene candidates for inclusion in screening panels, program structure, laboratory-clinical pipeline establishment, ethical, legal, social and financial implications must be both considered and evaluated in large, prospective studies to inform decisions regarding future implementation.

Acknowledgments: Jovanka King is a recipient of the Mike and Carole Ralston Travelling Fellowship 2016 from the RCPA Foundation.

Author Contributions: Jovanka King, Jonas F. Ludvigsson and Lennart Hammarström wrote the paper.

Conflicts of Interest: The authors declare no conflict of interest.

\section{References}

1. Itan, Y.; Shang, L.; Boisson, B.; Patin, E.; Bolze, A.; Moncada-Velez, M.; Scott, E.; Ciancanelli, M.J.; Lafaille, F.G.; Markle, J.G.; et al. The human gene damage index as a gene-level approach to prioritizing exome variants. Proc. Natl. Acad. Sci. USA 2015, 112, 13615-13620. [CrossRef] [PubMed]

2. Pai, S.Y.; Logan, B.R.; Griffith, L.M.; Buckley, R.H.; Parrott, R.E.; Dvorak, C.C.; Kapoor, N.; Hanson, I.C.; Filipovich, A.H.; Jyonouchi, S.; et al. Transplantation outcomes for severe combined immunodeficiency, 2000-2009. N. Engl. J. Med. 2014, 371, 434-446. [CrossRef] [PubMed]

3. Guthrie, R.; Susi, A. A simple phenylalanine method for detecting phenylketonuria in large populations of newborn infants. Pediatrics 1963, 32, 338-343. [PubMed]

4. Wilson, J.; Jungner, G. The principles and Practice of Screening for Disease; World Health Organization: Geneva, Switzerland, 1968. 
5. Kwan, A.; Abraham, R.S.; Currier, R.; Brower, A.; Andruszewski, K.; Abbott, J.K.; Baker, M.; Ballow, M.; Bartoshesky, L.E.; Bonilla, F.A.; et al. Newborn screening for severe combined immunodeficiency in 11 screening programs in the United States. JAMA 2014, 312, 729-738. [CrossRef] [PubMed]

6. Barbaro, M.; Ohlsson, A.; Borte, S.; Jonsson, S.; Zetterström, R.H.; King, J.; Winiarski, J.; von Döbeln, U.; Hammarström, L. Newborn screening for severe primary immunodeficiency diseases in sweden-a 2-year pilot trec and krec screening study. J. Clin. Immunol. 2017, 37, 51-60. [CrossRef] [PubMed]

7. Chan, K.; Puck, J.M. Development of population-based newborn screening for severe combined immunodeficiency. J. Allergy Clin. Immunol. 2005, 115, 391-398. [CrossRef] [PubMed]

8. Dorsey, M.; Puck, J. Newborn screening for severe combined immunodeficiency in the US: Current status and approach to management. Int. J. Neonatal Screen. 2017, 3, 15. [CrossRef]

9. Chien, Y.-H.; Yu, H.-H.; Lee, N.-C.; Ho, H.-C.; Kao, S.-M.; Lu, M.-Y.; Jaing, T.-H.; Lee, W.-I.; Chang, K.-W.; Shieh, C.-C.; et al. Newborn screening for severe combined immunodeficiency in Taiwan. Int. J. Neonatal Screen. 2017, 3, 16. [CrossRef]

10. Rechavi, E.; Lev, A.; Saraf-Levy, T.; Etzioni, A.; Almashanu, S.; Somech, R. Newborn screening for severe combined immunodeficiency in Israel. Int. J. Neonatal Screen. 2017, 3, 13. [CrossRef]

11. Blom, M.; Pico-Knijnenburg, I.; Sijne-van Veen, M.; Boelen, A.; Bredius, R.G.M.; van der Burg, M.; Schielen, P.C.J.I. An evaluation of the trec assay with regard to the integration of scid screening into the Dutch newborn screening program. Clin. Immunol. 2017, 180, 106-110. [CrossRef] [PubMed]

12. Audrain, M.; Thomas, C.; Mirallie, S.; Bourgeois, N.; Sebille, V.; Rabetrano, H.; Durand-Zaleski, I.; Boisson, R.; Persyn, M.; Pierres, C.; et al. Evaluation of the T-cell receptor excision circle assay performances for severe combined immunodeficiency neonatal screening on guthrie cards in a french single centre study. Clin. Immunol. 2014, 150, 137-139. [CrossRef] [PubMed]

13. De Felipe, B.; Olbrich, P.; Lucenas, J.M.; Delgado-Pecellin, C.; Pavon-Delgado, A.; Marquez, J.; Salamanca, C.; Soler-Palacin, P.; Gonzalez-Granado, L.I.; Antolin, L.F.; et al. Prospective neonatal screening for severe Tand B-lymphocyte deficiencies in Seville. Pediatr. Allergy Immunol. 2016, 27, 70-77. [CrossRef] [PubMed]

14. Kanegae, M.P.; Barreiros, L.A.; Mazzucchelli, J.T.; Hadachi, S.M.; de Figueiredo Ferreira Guilhoto, L.M.; Acquesta, A.L.; Genov, I.R.; Holanda, S.M.; Di Gesu, R.S.; Goulart, A.L.; et al. Neonatal screening for severe combined immunodeficiency in Brazil. J. Pediatr. (Rio J) 2016, 92, 374-380. [CrossRef] [PubMed]

15. Nakagawa, N.; Imai, K.; Kanegane, H.; Sato, H.; Yamada, M.; Kondoh, K.; Okada, S.; Kobayashi, M.; Agematsu, K.; Takada, H.; et al. Quantification of kappa-deleting recombination excision circles in Guthrie cards for the identification of early B-cell maturation defects. J. Allergy Clin. Immunol. 2011, 128, $223-225$. [CrossRef] [PubMed]

16. Borte, S.; von Döbeln, U.; Fasth, A.; Wang, N.; Janzi, M.; Winiarski, J.; Sack, U.; Pan-Hammarström, Q.; Borte, M.; Hammarström, L. Neonatal screening for severe primary immunodeficiency diseases using high-throughput triplex real-time PCR. Blood 2012, 119, 2552-2555. [CrossRef] [PubMed]

17. Bruton, O.C. Agammaglobulinemia. Pediatrics 1952, 9, 722-728. [PubMed]

18. Bruton, O.C. Agammaglobulinemia (congenital absence of gamma globulin); report of a case. Med. Ann. Dist. Columbia 1953, 22, 648-650. [PubMed]

19. Vetrie, D.; Vorechovsky, I.; Sideras, P.; Holland, J.; Davies, A.; Flinter, F.; Hammarstrom, L.; Kinnon, C.; Levinsky, R.; Bobrow, M.; et al. The gene involved in X-linked agammaglobulinaemia is a member of the src family of protein-tyrosine kinases. Nature 1993, 361, 226-233. [CrossRef] [PubMed]

20. Picard, C.; Al-Herz, W.; Bousfiha, A.; Casanova, J.L.; Chatila, T.; Conley, M.E.; Cunningham-Rundles, C.; Etzioni, A.; Holland, S.M.; Klein, C.; et al. Primary immunodeficiency diseases: An update on the classification from the international union of immunological societies expert committee for primary immunodeficiency 2015. J. Clin. Immunol. 2015, 35, 696-726. [CrossRef] [PubMed]

21. Grazioli, S.; Bennett, M.; Hildebrand, K.J.; Vallance, H.; Turvey, S.E.; Junker, A.K. Limitation of TREC-based newborn screening for ZAP70 severe combined immunodeficiency. Clin. Immunol. 2014, 153, 209-210. [CrossRef] [PubMed]

22. Hauck, F.; Blumenthal, B.; Fuchs, S.; Lenoir, C.; Martin, E.; Speckmann, C.; Vraetz, T.; Mannhardt-Laakmann, W.; Lambert, N.; Gil, M.; et al. Syk expression endows human ZAP70-deficient CD8 T cells with residual TCR signaling. Clin. Immunol. 2015, 161, 103-109. [CrossRef] [PubMed] 
23. Kuo, C.Y.; Chase, J.; Garcia Lloret, M.; Stiehm, E.R.; Moore, T.; Aguilera, M.J.; Lopez Siles, J.; Church, J.A. Newborn screening for severe combined immunodeficiency does not identify bare lymphocyte syndrome. J. Allergy Clin. Immunol. 2013, 131, 1693-1695. [CrossRef] [PubMed]

24. Lev, A.; Simon, A.J.; Broides, A.; Levi, J.; Garty, B.Z.; Rosenthal, E.; Amariglio, N.; Rechavi, G.; Somech, R. Thymic function in mhc class II-deficient patients. J. Allergy Clin. Immunol. 2013, 131, 831-839. [CrossRef] [PubMed]

25. Lyttle, A.; Roifman, C.; Dadi, H.; Wright, N.; Kavadas, F. MHC class II deficiency in the Dene native population: A case report highlighting pitfalls in diagnosis and treatment. Allergy Asthma Clin. Immunol. 2014, 10, A1. [CrossRef]

26. Speckmann, C.; Neumann, C.; Borte, S.; la Marca, G.; Sass, J.O.; Wiech, E.; Fisch, P.; Schwarz, K.; Buchholz, B.; Schlesier, M.; et al. Delayed-onset adenosine deaminase deficiency: Strategies for an early diagnosis. J. Allergy Clin. Immunol. 2012, 130, 991-994. [CrossRef] [PubMed]

27. Janzi, M.; Sjöberg, R.; Wan, J.; Fischler, B.; von Döbeln, U.; Isaac, L.; Nilsson, P.; Hammarström, L. Screening for C3 deficiency in newborns using microarrays. PLoS ONE 2009, 4, e5321. [CrossRef] [PubMed]

28. Hamsten, C.; Skattum, L.; Truedsson, L.; von Döbeln, U.; Uhlén, M.; Schwenk, J.M.; Hammarström, L.; Nilsson, P.; Neiman, M. Heat differentiated complement factor profiling. J. Proteom. 2015, 126, 155-162. [CrossRef] [PubMed]

29. Rosenfeld, M.; Sontag, M.K.; Ren, C.L. Cystic fibrosis diagnosis and newborn screening. Pediatr. Clin. N. Am. 2016, 63, 599-615. [CrossRef] [PubMed]

30. Borte, S.; Meeths, M.; Liebscher, I.; Krist, K.; Nordenskjold, M.; Hammarstrom, L.; von Dobeln, U.; Henter, J.I.; Bryceson, Y.T. Combined newborn screening for familial hemophagocytic lymphohistiocytosis and severe Tand B-cell immunodeficiencies. J. Allergy Clin. Immunol. 2014, 134, 226-228. [CrossRef] [PubMed]

31. Stranneheim, H.; Wedell, A. Exome and genome sequencing: A revolution for the discovery and diagnosis of monogenic disorders. J. Intern. Med. 2016, 279, 3-15. [CrossRef] [PubMed]

32. Pavey, A.R.; Bodian, D.L.; Vilboux, T.; Khromykh, A.; Hauser, N.S.; Huddleston, K.; Klein, E.; Black, A.; Kane, M.S.; Iyer, R.K.; et al. Utilization of genomic sequencing for population screening of immunodeficiencies in the newborn. Genet. Med. 2017. [CrossRef] [PubMed]

33. Boyle, J.M.; Buckley, R.H. Population prevalence of diagnosed primary immunodeficiency diseases in the United States. J. Clin. Immunol. 2007, 27, 497-502. [CrossRef] [PubMed]

34. Berg, J.S.; Agrawal, P.B.; Bailey, D.B.; Beggs, A.H.; Brenner, S.E.; Brower, A.M.; Cakici, J.A.; Ceyhan-Birsoy, O.; Chan, K.; Chen, F.; et al. Newborn sequencing in genomic medicine and public health. Pediatrics 2017, 139, e20162252. [CrossRef] [PubMed]

35. Friedman, J.M.; Cornel, M.C.; Goldenberg, A.J.; Lister, K.J.; Sénécal, K.; Vears, D.F.; The Global Alliance for Genomics and Health Regulatory and Ethics Working Group Paediatric Task Team. Genomic newborn screening: Public health policy considerations and recommendations. BMC Med. Genom. 2017, 10, 9. [CrossRef] [PubMed]

36. Tambe, P.; Sammons, H.M.; Choonara, I. Child mortality of children aged 5-15 years in the UK and Sweden: A comparison. Arch. Dis. Child. 2016, 101, 409-410. [CrossRef] [PubMed]

37. Tambe, P.; Sammons, H.M.; Choonara, I. Why do young children die in the UK? A comparison with sweden. Arch. Dis. Child. 2015, 100, 928-931. [CrossRef] [PubMed]

(C) 2017 by the authors. Licensee MDPI, Basel, Switzerland. This article is an open access article distributed under the terms and conditions of the Creative Commons Attribution (CC BY) license (http://creativecommons.org/licenses/by/4.0/). 